\title{
Hemifacial Spasm in Childhood
}

\author{
Gabriel M. Ronen, Jeffery R. Donat and Alan Hill
}

\begin{abstract}
A nine-year-old girl presented with right hemifacial spasm (HFS) of 27 months duration. Stimulation of the right supraorbital nerve produced synkinesis of the ipsilateral facial muscles. Latency and amplitude of the blink reflex were equal bilaterally. Other investigations including computerized tomography (CT) were negative. Treatment with carbamazepine was not helpful. This is the third reported case of HFS in childhood.
\end{abstract}

RÉSUMÉ: Le spasme de l'hémiface dans l'enfance Une fillette de 9 ans consulte pour un spasme de l'hémiface droite apparu 27 mois auparavant. La stimulation du nerf frontal externe droit produit des syncinésies des muscles faciaux ipsilatéraux. Le temps de latence et l'amplitude du réflexe de clignement sont égaux des deux côtés. Le reste de l'investigation, incluant la tomographie assistée par ordinateur s'est révélée négative. Le traitement par la carbamazépine n'a donné aucun résultat. Ceci constitue le troisième cas rapporté dans la littérature de spasme hémifacial de l'enfance.

Can. J. Neurol. Sci. 1986; 13:342-343

Hemifacial spasm is characterized by involuntary, irregular twitching of muscles innervated by the facial nerve. ${ }^{1,2,3}$ It occurs almost exclusively in adults; only two cases have been reported in children. ${ }^{4,5}$ The differential diagnosis includes focal seizures, tics, essential blepharospasm, focal dystonia, tardive dyskinesia, segmental myoclonus and facial myokymia.

\section{CASE REPORT}

The patient was a nine-year-old girl who presented with intermittent, right HFS of 18 months duration. There was no history of prior facial nerve palsy or injury. There was no family history of similar problems. Initially, the twitching involved only the periorbital muscles. Over the subsequent year, other facial muscles became involved. The spasm lasted approximately 20 seconds and began with involuntary eyelid closure and repetitive eyelid twitching followed by facial spasm with pulling of the mouth (Figure 1). During the spasm, a noise was heard in the ipsilateral ear. The spasm could be triggered by voluntary facial movements or by hyperventilation. It could not be suppressed.

The strength of the facial muscles was normal. A pure-tone audiogram, brainstem auditory evoked potentials, EEG, CT scan, skull $x$-ray and tomograms with special views of the internal auditory and facial nerve canals were normal.

Stimulation of each supraorbital nerve produced a blink reflex with latency to the onset of the early $(\mathrm{R}-1)$ response of $10.0 \mathrm{~ms}$ and amplitude of $0.6 \mathrm{mv}$. Stimulation of the right supraorbital nerve resulted in synkinesis of the ipsilateral orbicularis oris muscle (Figure 2a). Stimulation of the contralateral nerve showed no synkinesis (Figure 2b). Synkinesis was observed on six successive occasions of stimulation of the right supraorbital nerve.
The HFS remained unchanged despite treatment with carbamazepine in anticonvulsant doses.

\section{Discussion}

The clinical features of this patient are consistent with a diagnosis of HFS. ${ }^{2,3}$ Electrical stimulation of the right supraorbital nerve produced synkinesis of the ipsilateral orbicularis oris muscle. Because synkinesis does not occur in focal epilepsy, tics, essential blepharospasm, orofacial dyskinesia or facial myokymia, ${ }^{6}$ this electrophysiological study may be used to support the diagnosis of HFS.

HFS may result from aberrant regeneration of the facial nerve following injury. In adults, compression of the facial nerve by overriding vessels in the cerebellopontine angle at the brainstem is the most common established cause of HFS. ${ }^{7.8}$ Rare causes include tumour, aneurysm and arteriovenous malformation. The absence of facial nerve palsy or injury and the normal investigations in our patient make these diagnoses unlikely.

There have been 2 children with HFS reported in the literature. One child had a ganglioneuroma of the fourth ventricle which was diagnosed more than five years following the onset of symptoms. ${ }^{4}$ This case emphasizes the necessity for close surveillance. No etiology could be established in the other patient, and the symptoms disappeared following six weeks of treatment with carbamazepine. ${ }^{5}$ Our patient did not respond to three months of treatment with carbamazepine. 


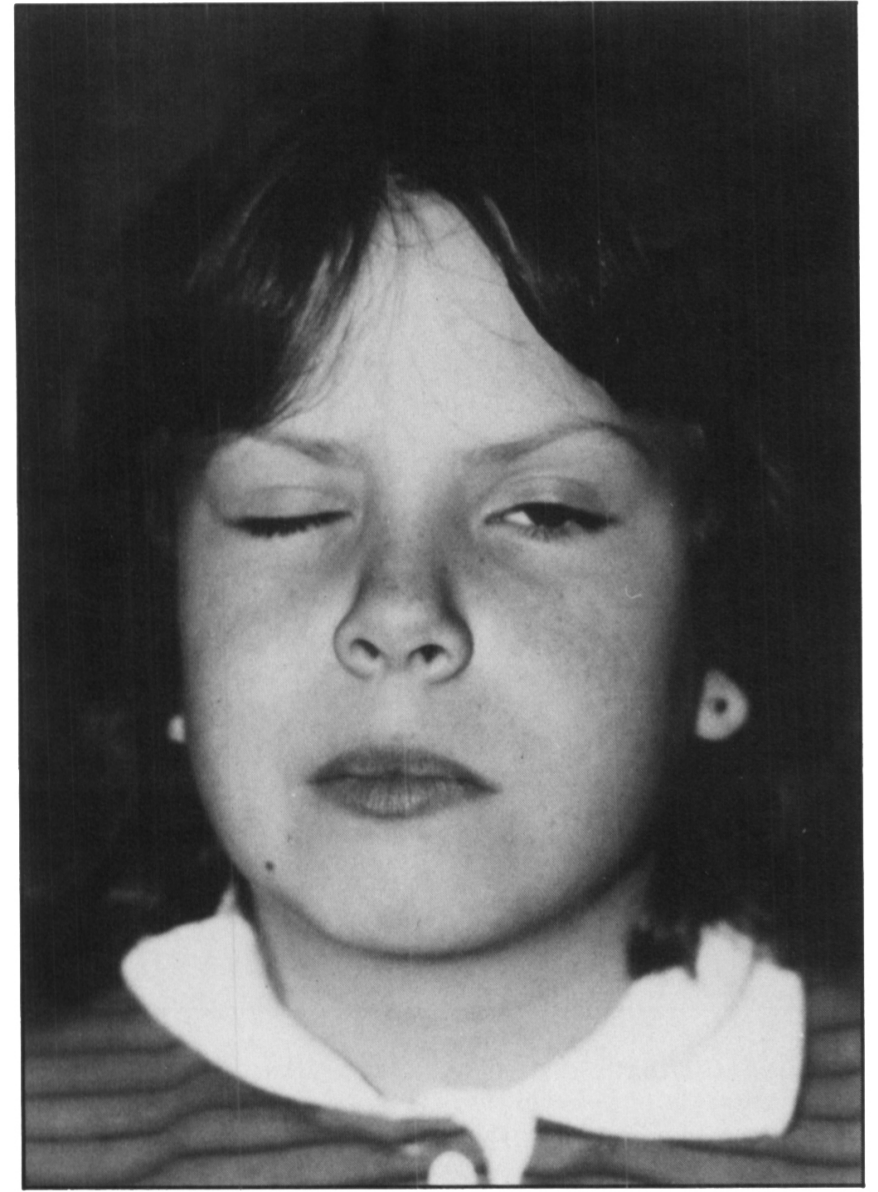

Figure I - Face during an episode of hemifacial spasm. Note eye closure and pulling of mouth to right.

\section{REFERENCES}

1. Gowers WR. A Manual of Diseases of the Nervous System. Philadelphia, P. Blakiston and Company 1888; pp. 600-699.

2. Ehni G, Woltman HW. Hemifacial spasm: review of one hundred and six cases. Arch Neurol Psychiatry 1945; 53: 205-211.

3. Nielsen VK. Pathophysiology of hemifacial spasm: 1. Ephaptic transmission and ectopic excitation. Neurology 1984; 34: 418-426.

4. Langstron JW, Tharp BR. Infantile hemifacial spasm. Arch Neurol $1974: 31: 63$.
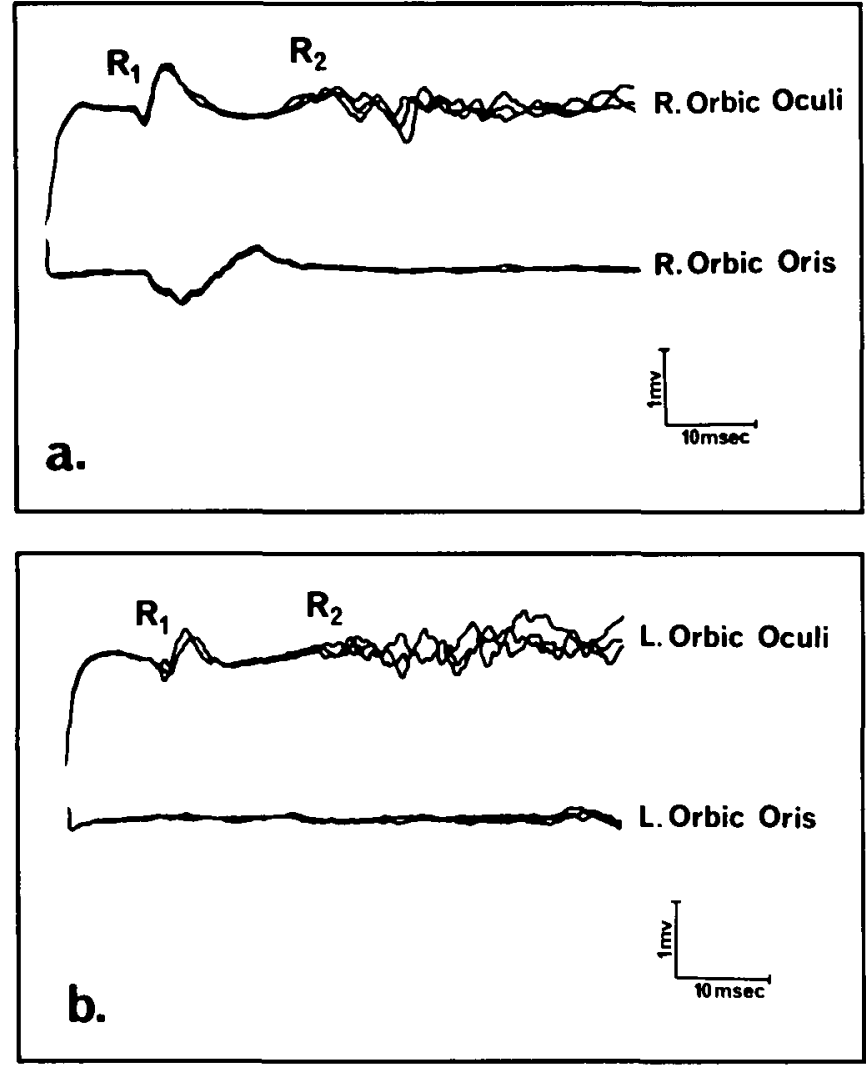

Figures $2 a$ and $2 b-$ Responses to supraorbital nerve stimulation. Simultaneous recording from orbicularis oculi and orbicularis oris muscles. (a) with right supraorbital nerve stimulation, the orbicularis oris contracts simultaneously with the orbicularis oculi (synkinesis); (b) with left supraorbital nerve stimulation, no synkinesis. $R_{1}-$ early response, $R_{2}-$ late response.

5. Shaywitz BA. Hemifacial spasm in childhood treated with carbamazepine. Arch Neurol 1974; 31: 63 .

6. Auger RG. Hemifacial spasm: clinical and electrophysiologic observations. Neurology (NY) 1979; 29: 1261-1272.

7. Jannetta PJ. Hemifacial spasm. In: Samii M, Jannetta PJ, eds. The cranial nerves. New York: Springer-Verlag 1981; pp. 484-493.

8. Nielsen VK, Janetta PJ. Pathophysiology of hemifacial spasm: III. Effects of facial nerve decompression. Neurology 1984:34: 891-897. 